\title{
Ontario ends weight-loss surgery abroad
}

I ncreased support for weight-loss surgery in Ontario has stemmed medical tourism to the United States and other countries, Health Quality Ontario (HQO) reveals in a report.

The Ontario Health Technology Maps Project Report highlights trends in the use of 21 tests and procedures on which the agency has issued recommendations.

According to the report, which was released Apr. 28, no Ontarians travelled abroad for bariatric surgery to treat morbid obesity in 2011/12 which is a "dramatic decline" from 2009/10, when nearly 2000 had the surgery outside Canada.

Dr. Les Levin, vice-president of evidence development and standards at HQO, says the change is a "heartening" example of how quickly the health system can respond to new evidence.

In 2005, his unit called on the province to increase support for bariatric surgery to prevent residents from being forced to seek the procedure elsewhere. Ontario has since created a bariatric treatment network, including four centres of excellence and six regional treatment and assessment centres, with the capacity to perform 2800 surgeries per year.

The report also spotlights progress in the treatment of epilepsy and urinary incontinence, as well as the judicious use of laboratory testing. Other recommendations to prevent falls and some invasive procedures have been less successful.

In 2013, a HQO analysis revealed that more than 6000 Ontarians with drug-resistant epilepsy could benefit from surgery to remove the part of their brain causing seizures.

"The procedure is curative in about $77 \%$ of cases," says Levin, but the health system lacked capacity to provide it. "As a result, the province provided $\$ 8.675$ million for epilepsy services to create 21 additional surgical beds and start screening these people for treatment."

Although too soon to declare a trend, this year's analysis indicates that the number of surgical resections for drug-

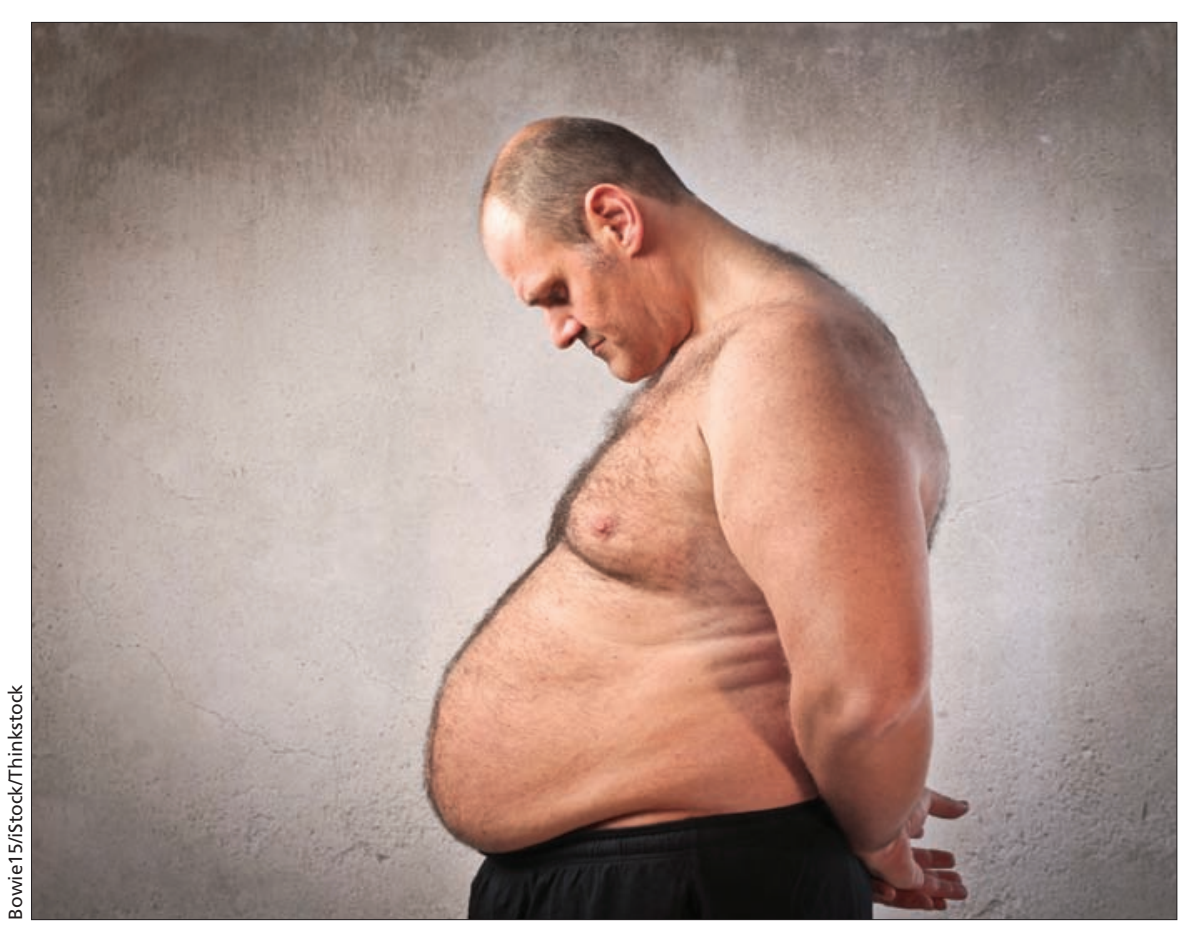

Medical tourism outside Ontario for surgery to treat morbid obesity has declined dramatically with the creation of a bariatric treatment network.

resistant epilepsy has increased to 145 procedures annually. That number could potentially increase to just over 300 per year.

"We're possibly the first jurisdiction in the world that's taking this approach," says Levin. "I'm really hoping we can help more people over the next few years."

The report also shows a steady up take of less invasive surgery for stress urinary incontinence after HQO demonstrated the benefit of miduretharal slings over the more involved colposuspension procedure.

In addition, bone mineral density testing in low-risk patients "declined rapidly" after reaching peak volumes in 2007/08, following a HQO recommendation to increase testing intervals from two to five years.

HQO-recommended interventions to prevent falls and improve treatment of dysfunctional uterine bleeding appear less successful. The report indicates a slight increase in the rate of falls and fall-related fractures requiring hospitalization among seniors since 2003/04, despite the efforts of an Integrated Provincial Falls Prevention Project that was initiated in that period.

Similarly, rates of hysterectomy to treat dysfunctional uterine bleeding remain higher than use of a less invasive treatment - thermal balloon endometrial ablation (TBEA) — recommended nine years ago.

"This is really demonstrating no significant improvement, and it's prompting us to go back and see if we've missed something," says Levin. In the case of TBEA, "it turns out there are other technologies out there that are simpler and can do the job better."

This is the fourth year the agency has reported on uptake of its recommendations. According to Levin, future reports will also set benchmarks for the tests and procedures tracked. - Lauren Vogel, CMAJ

CMAJ 2014. DOI:10.1503/cmaj.109-4800 